\title{
Metabolism and Disposition of Ataluren after Oral Administration to Mice, Rats, Dogs, and Humans
}

\author{
Ronald Kong, Jiyuan Ma, Seongwoo Hwang, Elizabeth Goodwin, Valerie Northcutt, John Babiak, \\ Neil Almstead, and Joseph Mclntosh
}

PTC Therapeutics Inc., South Plainfield, New Jersey

Received September 21, 2019; accepted January 4, 2020

\begin{abstract}
Ataluren is a unique small molecule developed for the treatment of diseases caused by nonsense mutations, which result in premature termination of ribosomal translation and lack of full-length protein production. This study investigated the in vivo metabolism and disposition of ataluren in mice, rats, dogs, and humans. After single oral administration of $\left[{ }^{14} \mathrm{C}\right]$ ataluren, the overall recovery of radioactivity was $\geq 93.7 \%$, with approximately $39 \%, 17 \%-21 \%, 12 \%$, and $55 \%$ in the urine and $54 \%, 70 \%-72 \%, 80 \%$, and $47 \%$ in the feces from intact mice, rats, dogs, and humans, respectively. In bile duct-cannulated (BDC) rats, approximately $10 \%, 7 \%$, and $82 \%$ of the dose was recovered in the urine, feces, and bile, respectively, suggesting that biliary secretion was a major route for the elimination of ataluren in the rats. Ataluren was extensively metabolized after oral administration, and the metabolic profiles of ataluren were quantitatively similar across all species. Unchanged ataluren was the dominant radioactive component in plasma. Ataluren acyl
\end{abstract}

glucuronide was the most prominent metabolite in plasma of all species and the dominant metabolite in BDC rat bile and human urine, whereas the oxadiazole cleavage products were the major or prominent metabolites in the feces of all species. Overall, the results indicate that phase I metabolism is negligible and that the pathway largely involves glucuronidation. No other circulatory conjugation metabolite was detected across investigated species.

\section{SIGNIFICANCE STATEMENT}

Ataluren is a novel carboxylic acid-containing small molecule drug for treating nonsense mutation Duchenne muscular dystrophy. In vivo metabolism and disposition after a single dose of the drug were investigated in mice, rats, dogs, and humans. Phase I metabolism of ataluren was negligible, and the pathway largely involves glucuronidation. No other circulatory conjugation metabolite was detected across investigated species.

\section{Introduction}

Ataluren is a novel carboxylic acid-containing small molecule drug developed for the treatment of diseases resulting from nonsense mutations. When a nonsense mutation (stop codon) is present, ribosomal translation of mRNA is prematurely terminated, resulting in the absence of a full-length functional protein. Ataluren enables the ribosome to read through a premature termination codon in mRNA so that translation continues as normal, and consequently, a functional full-length protein is produced (Welch et al., 2007). The selectivity of ataluren for premature termination codons, its well characterized activity profile, its oral bioavailability, and its good tolerability in animals and humans indicate that ataluren may have broad clinical potential for the treatment of nonsense mutations that result in a stop codon in the protein-coding region of mRNA (Culbertson, 1999; Mendell and Dietz, 2001).

Ataluren has demonstrated treatment benefit in patients with nonsense mutation Duchenne muscular dystrophy (nmDMD). Duchenne muscular dystrophy is an X-linked genetic muscle disorder that results from the presence of mutations in the dystrophin gene (Petrof et al., 1993; Bushby

This work was supported by PTC Therapeutics, Inc. https://doi.org/10.1124/dmd.119.089391. et al., 2010a,b; Mah, 2016). Dystrophin mutations result in chronic muscle damage, inflammation, and eventually replacement of muscle fibers by fat and fibrotic tissue, resulting in progressive and irreversible loss of muscle function (Muntoni et al., 2003). The progressive loss of muscle function causes loss of ambulation, ongoing impairment of respiratory and cardiac function, and early death (Henricson et al., 2013).

In approximately $10 \%-15 \%$ of boys with Duchenne muscular dystrophy, the disease is caused by a nonsense mutation (Aartsma-Rus et al., 2006; Bladen et al., 2015). Ataluren has demonstrated the ability to promote dystrophin production in nmDMD muscle and to slow disease progression in patients with nmDMD (Finkel et al., 2013; Bushby et al., 2014; McDonald et al., 2017). Ataluren is the only therapy that directly addresses the underlying cause of nmDMD.

A series of in vitro studies, e.g., metabolism in liver microsomes, uridine diphosphate glucuronosyltransferase (UGT) reaction phenotyping, enzyme kinetics for ataluren glucuronidation, CYP inhibition, and induction potentials, have been conducted for ataluren (Kong et al. manuscript submitted). In vitro metabolism studies showed that the major metabolic pathway for ataluren is via direct glucuronidation and that UGT1A9 is the major enzyme responsible for ataluren glucuronidation.

In vivo metabolism and disposition information is critical in all phases of a fully integrated drug development program, and these studies are

ABBREVIATIONS: AUC, area under the plasma concentration-time curve; BDC, bile duct-cannulated; $\mathrm{C}_{\text {max }}$, maximum concentration; CMC, carboxymethylcellulose; HPLC, high-performance liquid chromatography; LC/MS: liquid chromatography/mass spectrometry LSC, liquid scintillation counting; nmDMD, nonsense mutation Duchenne muscular dystrophy; MS/MS or $\mathrm{MS}^{2}$ double-stage mass spectrometry PES, postextraction solid; $\mathrm{m} / \mathrm{z}$ mass-to-charge ratio $\mathrm{PK}$, pharmacokinetic; $t_{1 / 2}$, terminal half-life; $\mathrm{T}_{\max }$, time to maximum concentration; TRA, total radioactivity; UGT, uridine diphosphate glucuronosyltransferase. 
typically performed with radiolabeled material to provide detailed quantitative information on the parent drug and its metabolites. This is particularly true for the treatment of nmDMD, which requires chronic administration of the drug over many years. The aim of this study was to evaluate the metabolism and disposition of ataluren in mice, rats, dogs, and humans after single oral administration of ataluren.

\section{Materials and Methods}

\section{Chemicals}

Ataluren ( $\geq 99.8 \%$ purity) was manufactured by Siegfried (Zofingen, Switzerland), and $\left[{ }^{14} \mathrm{C}\right]$ ataluren $(>57 \mathrm{mCi} / \mathrm{mmol}, \geq 98 \%$ radiochemical and chemical purity) was synthesized by $\mathrm{ABC}$ laboratories (Columbia, MO) for animal studies and by GE Healthcare Amersham Place (Little Chalfont, Buckinghamshire, UK) for human dosing. Ataluren- $O-1 \beta$-acyl glucuronide was synthesized at PTC Therapeutics, Inc. (South Plainfield, NJ). Acetonitrile, isopropanol, and methanol were obtained from EM Science (Gibbstown, NJ). Formic acid, ammonium acetate, and ammonium hydroxide were purchased from Mallinckrodt Baker (Phillipsburg, NJ). ${ }^{14} \mathrm{C}$ liquid scintillation cocktail was obtained from R.J. Harvey Instrument Corporation (Tappan, NY). Ready Safe and Ready Value liquid scintillation cocktails were purchased from Beckman Instruments (Brea, CA).

\section{Methods}

Study Design and Sample Collection. All animal studies have been carried out in accordance with the Guide for the Care and Use of Laboratory Animals as adopted and promulgated by the US National Institutes of Health and were approved by the institution's animal care and use committee. The human study has been carried out in accordance with the Declaration of Helsinki and the International Council for Harmonization Good Clinical Practice. The institutional review board reviewed and approved the clinical study protocol, any clinical study protocol amendments, subject information sheets, written informed consent forms, and other relevant documentation. Prior to participation in the study, each subject was apprised of the nature and purpose of the study, and informed consent was obtained.

Mouse Study. The transgenic mouse model used in carcinogenicity study was also used in this study. In total, 42 male Tg.rasH2 wild-type mice (Taconic, Hudson, NY), 8-10 weeks old and 24-34 g in body weight, were each administered an oral dose of $\left[{ }^{14} \mathrm{C}\right]$ ataluren at a target dose of $300 \mathrm{mg} / \mathrm{kg}$ or $100 \mu \mathrm{Ci} / \mathrm{kg}$. The animals were not fasted prior to dosing. $\left[{ }^{14} \mathrm{C}\right]$ ataluren dose suspension $(20 \mathrm{mg} / \mathrm{ml}$ or $6.7 \mu \mathrm{Ci} / \mathrm{ml})$ in $0.5 \%$ carboxymethylcellulose $(\mathrm{CMC})$ was administered by oral gavage in a dose volume of $15 \mathrm{ml} / \mathrm{kg}$. Urine samples were collected at the time intervals $0-8,8-24,24-48,48-72,72-96$, and 96-120 hours, and feces were collected at 24-hour intervals until 120 hours postdose for group 1 mice $(n=9)$. Cages were rinsed with water at 24-hour intervals until 96 hours postdose and thoroughly washed with isopropanol:water $(1: 1, \mathrm{v} / \mathrm{v})$ at 120 hours postdose.

For group 2 mice $(n=33)$, three mice per time point were anesthetized using $\mathrm{CO}_{2}$ at $0.33,0.67,1,1.5,2,4,8,12,24,48$, and 72 hours postdose, and blood samples (up to approximately $1 \mathrm{ml}$ ) were collected via cardiac puncture using 1-ml tuberculin syringes containing $\mathrm{K}_{3}$ EDTA. An equal volume of blood from each animal was pooled per time point based on the lowest blood volume of the three animals. The pooled blood was mixed well by gently inverting the tube (at least 10 times) and was kept on ice. A duplicate $50 \mu \mathrm{l}$ of blood was taken for combustion. The remaining blood was centrifuged at $1400 \mathrm{~g}$ and $4^{\circ} \mathrm{C}$ for 10 minutes to separate plasma. Urine and fecal samples were stored at $-20^{\circ} \mathrm{C}$, and plasma was stored at $-70 \pm 5^{\circ} \mathrm{C}$.

Rat Study. Intact (group 1, three rats per sex), bile duct-cannulated (BDC) (group 2, three rats per sex), and jugular vein-cannulated (group 3, 13 rats per sex) Sprague-Dawley rats were used in this study. Each were administered an oral dose of $\left[{ }^{14} \mathrm{C}\right]$ ataluren at a target dose of $100 \mathrm{mg} / \mathrm{kg}$ or $75 \mu \mathrm{Ci} / \mathrm{kg}$. The rats were approximately 7-11 weeks old and weighed 212-283 g (group 1), 244-294 g (group 2), and 272-324 g (group 3) at the time of dosing. The rats were not fasted: food and fresh tap water (electrolyte-supplemented water, sodium chloride: potassium chloride:glucose, 0.925:0.05:5.06\%, w/v, for BDC rats) were available ad libitum. $\left[{ }^{14} \mathrm{C}\right]$ ataluren dose suspension (approximately $10 \mathrm{mg} / \mathrm{ml}$ or $8 \mu \mathrm{Ci} / \mathrm{ml}$ ) in $0.5 \% \mathrm{CMC}$ was administered by oral gavage in a dose volume of $10 \mathrm{ml} / \mathrm{kg}$.
Urine samples were collected at 0-8 hours, 8-24 hours, and 24-hour intervals until 96 (group 1) or 72 hours (group 2) postdose. Cages were rinsed with water at 24-hour intervals to 72 (group 1) or 48 hours (group 2) postdose and thoroughly washed with isopropanol:water (1:1, v/v) at 96 (group 1) or 48 hours (group 2) postdose. Feces were collected at 24-hour intervals for 72 (group 2) or 96 hours (group 1). Bile was collected from BDC rats at predose and at $0-4,4-8,8-24$, 24-48, and 48-72 hours postdose. Blood samples (approximately $1 \mathrm{ml}$ ) were collected from the cannulated jugular vein (or about $5 \mathrm{ml}$ by cardiac puncture for terminal time point) of the rats in group 3 at $0.25,0.5,1,1.5,2,3,4,8,12,24$, and 48 hours postdose. At the terminal time point, rats were anesthetized using $\mathrm{CO}_{2}$. Blood was mixed by inverting the tube. A duplicate $50 \mu \mathrm{l}$ of blood was taken for combustion. The remaining blood was centrifuged at $4^{\circ} \mathrm{C}$ and $1400 \mathrm{~g}$ for 10 minutes to separate plasma. $\mathrm{K}_{3}$ EDTA was used as an anticoagulant. Plasma was stored at $-70 \pm 5^{\circ} \mathrm{C}$, and all other samples were stored at $-20^{\circ} \mathrm{C}$.

Dog Study. Three male beagle dogs were used in this study. Each dog was administered an oral dose of $\left[{ }^{14} \mathrm{C}\right]$ ataluren at a target dose of $250 \mathrm{mg} / \mathrm{kg}$ or $7.5 \mu \mathrm{Ci} / \mathrm{kg}$. The dogs were approximately 5 years old and weighed $7.0-8.4 \mathrm{~kg}$ at the time of dosing. The dogs were fasted overnight before dosing and 4 hours after dosing, and fresh tap water was available ad libitum. $\left[{ }^{14} \mathrm{C}\right]$ ataluren dose suspension $(125 \mathrm{mg} / \mathrm{ml}$ or $3.75 \mu \mathrm{Ci} / \mathrm{ml})$ in $0.5 \% \mathrm{CMC}$ was administered by oral gavage in a dose volume of $2 \mathrm{ml} / \mathrm{kg}$.

Urine samples were collected at 0-8 hours, 8-24 hours, and at 24-hour intervals until 168 hours postdose. Cages were rinsed with water at 24-hour intervals to 144 hours postdose and thoroughly washed with isopropanol:water $(1: 1, v / v)$ at 168 hours postdose. Feces were collected at 24-hour intervals for 168 hours. Blood samples $(\sim 3-4 \mathrm{ml})$ were collected from the cephalic vein of the dog predose and at $0.25,0.5,1,2,4,8,12,24,32,48$, and 72 hours postdose. $\mathrm{K}_{3}$ EDTA was used as an anticoagulant. Blood was centrifuged at $4{ }^{\circ} \mathrm{C}$ and $1400 \mathrm{~g}$ for 10 minutes to separate plasma. Plasma samples were acidified with $5 \%$ formic acid $\left(200 \mu \mathrm{l} / \mathrm{g}\right.$ of plasma). Plasma was stored at $-70 \pm 5^{\circ} \mathrm{C}$, and all other samples were stored at $-20^{\circ} \mathrm{C}$.

Human Study. The clinical phase of the study was conducted at Covance Laboratories Inc. (Madison, WI). Seven healthy male subjects, 18-55 years of age, were recruited in this open-label study. After at least 8 hours of fasting overnight, each subject received a single oral dose of ataluren aqueous suspension in water containing $1375 \mathrm{mg}$ of unlabeled ataluren and $96.6 \mu \mathrm{Ci}$ of $\left[{ }^{14} \mathrm{C}\right]$ ataluren (approximately $0.5 \mathrm{mg}$ ).

Blood samples were collected at predose; at $0.5,1,1.5,2,3,4,6,8,12,16,24$, 36 , and 48 hours; and at 24 -hour intervals to 240 hours postdose in all subjects. Urine and fecal samples were collected continuously over 24-hour intervals up to 240 hours or until radioactivity in the sample was $1 \%$ of the administered dose (the maximum in-house stay for subjects was 15 days postdose). All samples were stored at $-70 \pm 5^{\circ} \mathrm{C}$.

\section{Sample Preparation for Radioactivity Determination}

Plasma was mixed by vortexing. Duplicate subsamples of plasma were prepared, weighed (approximately $0.05 \mathrm{~g}$ ), mixed with scintillation cocktail, and counted directly by liquid scintillation counting (LSC). Duplicate aliquots of blood (approximately $0.05 \mathrm{~g}$ ) were weighed into combustion boats and combusted using a biologic sample oxidizer (R.J. Harvey Instrument Corporation) followed by LSC counting.

Urine and cage rinse/wash were each thoroughly mixed, and duplicate aliquots (approximately $0.1 \mathrm{ml}$ for urine and $1 \mathrm{ml}$ for cage rinse/wash) were weighed into scintillation vials, mixed with scintillation cocktail, and assayed directly by LSC. Feces were homogenized with an approximately $3 \times(\mathrm{w} / \mathrm{v})$ mixture of isopropanol:water $(1: 1, \mathrm{v} / \mathrm{v})$, and triplicate aliquots of homogenate, equivalent to approximately $100 \mathrm{mg}$ of fresh feces weight, were combusted in an oxidizer followed by LSC counting. When samples were expected to contain very high radioactivity, smaller sample sizes were analyzed.

\section{Sample Preparation for Metabolite Profiling}

Plasma. Pooled or individual plasma samples (equal volumes from individual animals were pooled at the following time points: $0.33,0.67,1,1.5,2,4,8,12$, and 24 hours for mouse; $0.25,0.5,1,4,12,24$, and 48 hours for rat; $0.25,1,2,4,8,12$, and 24 hours for dog; and individual plasma samples from seven human subjects at $0.5,1,2,4,8,12$, and 24 hours) were selected by concentration of total radioactivity (TRA) in plasma. The selected plasma sample was mixed with 
TABLE 1

Percentage of dose recovered after single oral administration of $\left[{ }^{14} \mathrm{C}\right]$ ataluren to mice, rats, dogs, and humans

\begin{tabular}{|c|c|c|c|c|c|c|c|c|}
\hline \multirow{2}{*}{ Species } & \multirow{2}{*}{ Sex } & \multirow{2}{*}{ Dose } & \multirow{2}{*}{ Collection Period (h) } & \multicolumn{5}{|c|}{ Percent of Dose Recovered (Mean \pm S.D.) } \\
\hline & & & & Urine & Bile & Feces & Cage/Rinse & Total \\
\hline Mouse & Male & $300 \mathrm{mg} / \mathrm{kg}$ & $0-120$ & $39.04 \pm 2.05$ & NA & $54.43 \pm 1.79$ & $3.79 \pm 0.60$ & $97.26 \pm 0.29$ \\
\hline \multirow[t]{2}{*}{$\mathrm{BDC}$ rat } & Male & $100 \mathrm{mg} / \mathrm{kg}$ & 0-96 (0-72 h for BDC rat) & $10.53 \pm 0.71$ & $81.92 \pm 0.97$ & $6.49 \pm 0.70$ & $0.56 \pm 0.24$ & $99.50 \pm 1.22$ \\
\hline & Female & & & $10.13 \pm 3.97$ & $82.13 \pm 4.66$ & $6.80 \pm 1.62$ & $1.20 \pm 0.70$ & $100.26 \pm 5.04$ \\
\hline \multirow[t]{2}{*}{ Intact rat } & Male & & & $20.87 \pm 1.03$ & NA & $72.44 \pm 1.75$ & $3.45 \pm 0.70$ & $96.77 \pm 0.81$ \\
\hline & Female & & & $17.08 \pm 5.57$ & NA & $69.77 \pm 7.06$ & $8.25 \pm 5.58$ & $95.11 \pm 4.26$ \\
\hline Dog & Male & $250 \mathrm{mg} / \mathrm{kg}$ & $0-168$ & $11.96 \pm 7.49$ & NA & $79.94 \pm 8.43$ & $1.84 \pm 0.45$ & $93.73 \pm 0.87$ \\
\hline Human & Male & $1375 \mathrm{mg}$ & $0-96$ & $55.10 \pm 10.30$ & NA & $47.30 \pm 12.40$ & NA & $103.00 \pm 7.00$ \\
\hline
\end{tabular}

NA, not available.

$3 \times$ volume of acetonitrile and vortexed, followed by centrifugation at $10,000 \mathrm{~g}$ and $4^{\circ} \mathrm{C}$ for 10 minutes. The pellets were rinsed twice with $3 \times$ volume of acetonitrile. The acetonitrile extract and rinsates were combined and evaporated to dryness under a $\mathrm{N}_{2}$ stream. The residues were reconstituted with an appropriate volume of acetonitrile:water $(1: 1, \mathrm{v} / \mathrm{v})$ for radio profiling.

Urine and Bile. The urine and bile samples were centrifuged at $10,000 \mathrm{~g}$ and $4^{\circ}$ $\mathrm{C}$ for 10 minutes, and the supernatants were subjected to high-performance liquid chromatography (HPLC) radio profiling.

Feces. An equal percentage by weight of fecal homogenates were pooled by time interval. The fecal homogenate was extracted three times with three volumes of acetonitrile by shaking for 10 minutes using a Wrist Action Shaker (Burrell Corporation, Northbrook, IL), followed by centrifugation at $1800 \mathrm{~g}$ for 10 minutes to separate the acetonitrile extract from the postextraction solids (PESs). The PESs were extracted with acetonitrile twice as described above. The three acetonitrile extracts were combined and evaporated to dryness at room temperature under a $\mathrm{N}_{2}$ stream. The resulting radioactive residues were reconstituted with a small volume of acetonitrile:water $(1: 1, \mathrm{v} / \mathrm{v})$ for radio-HPLC analysis.

\section{Determination of Radioactivity}

Levels of radioactivity in plasma, urine, and cage rinse/wash samples were determined by counting aliquots directly in a liquid scintillation counter (Beckman Instruments). The evolved $\left[{ }^{14} \mathrm{C}_{\mathrm{CO}_{2}}\right.$ - either from blood, feces, or PES that was combusted in a biologic sample oxidizer-was counted in $15 \mathrm{ml}$ of Harvey Scintillation Carbon-14 Cocktail.

\section{Determination of HPLC Column Recovery}

The selected plasma, urine, and fecal samples were injected onto an HPLC column under the same conditions as those used for metabolite profiling. The effluent was collected and analyzed by LSC. The data were compared with those obtained without use of an HPLC column to determine the HPLC column recovery of radioactivity. Column recoveries for the selected samples were from $87.1 \%$ to $100 \%$.

\section{Determination of Metabolite Profiles}

The metabolic profiles were determined by HPLC radiochromatography using a Waters 2695 HPLC system. An Ace 3 C18 column $(3 \mu \mathrm{m}, 150 \times 4.6 \mathrm{~mm}$; MAC-MOD Analytical, Inc., Chadds Ford, PA) maintained at $30^{\circ} \mathrm{C}$ and two solvent systems of $0.4 \%$ formic acid in water, $\mathrm{pH} 3.2$, adjusted with ammonium hydroxide (A) and 100\% acetonitrile (B) were used. The flow rate was $0.7 \mathrm{ml} / \mathrm{min}$, and the linear gradients were $0 \% \mathrm{~B}$ for 5 minutes; $0 \%-5 \% \mathrm{~B}$ in 5 minutes; $5 \%-70 \%$ B in 50 minutes, $70 \%-95 \%$ B in 5 minutes, hold $95 \%$ B for 5 minutes; $95 \%-0 \%$ B in 2 minutes and hold $0 \%$ B for 15 minutes. HPLC fractions were collected by time ( 15 seconds per fraction) to Deepwell LumaPlate-96 plates (PerkinElmer Life Sciences, Waltham, MA). The plates were subsequently dried by a SpeedVac concentrator (Savant Instruments Inc., Holbrook, NY) for up to 8 hours. The radioactivity in each fraction was determined by Packard TopCount NXT Microplate Scintillation and Luminescence Counter technology (PerkinElmer Life Sciences). HPLC radiochromatograms were reconstructed using ARC Convert and Evaluation software (version 1.0; AIM Research Company, Hockessin, DE). Radioactivity peaks were integrated to determine the percent distribution of individual radioactivity peaks or regions in each sample.

\section{Metabolite Identification}

LC/MS Analysis. Bile, urine, and the extracts of plasma and fecal samples were analyzed by liquid chromatography-tandem mass spectrometry using an LTQ ion trap mass spectrometer (Thermo Fisher Scientific, Waltham, MA) and a QSTAR XL MS/MS System (AB Sciex, Foster City, CA). The LTQ was equipped with an electrospray ionization source operated in positive ion mode with a capillary temperature of $320^{\circ} \mathrm{C}$ and spray voltage of $5 \mathrm{kV}$. The sheath gas, auxiliary gas, and sweep gas pressure was 70, 20, and $5 \mathrm{U}$, respectively, and the tube lens voltage was set at $130 \mathrm{~V}$. The QSTAR XL MS/MS System was operated under turbo ion spray in the positive ion mode with a turbo probe temperature of $500^{\circ} \mathrm{C}$ and ion spray voltage of $5 \mathrm{kV}$. The pressure for nebulizer gas, turbo gas, and curtain gas was set at 30,30 , and 20 psi, respectively.

Conversion of M2 to M3. Approximately $0.4 \mathrm{mg}$ of synthetic M2 standard was dissolved in $1.0 \mathrm{ml}$ of methanol. A $100-\mu \mathrm{l}$ aliquot of the methanolic solution was mixed with $200 \mu \mathrm{l}$ water and $150 \mu \mathrm{l}$ of concentrated ammonium hydroxide. The mixture was sealed in an HPLC vial and heated at $50^{\circ} \mathrm{C}$ for approximately 5 hours.

Conversion of M4 to M5. A 100- $\mu 1$ aliquot of synthetic M4 standard solution at $0.3 \mathrm{mg} / \mathrm{ml}$ in methanol:water $(1: 1, \mathrm{v} / \mathrm{v})$ was mixed with $20 \mu \mathrm{l}$ of $0.4 \%$ aqueous formic acid (pH 3.2) in an HPLC vial. The mixture was heated at $37^{\circ} \mathrm{C}$ for 2 hours.

\section{Pharmacokinetic Analysis}

Pharmacokinetic (PK) parameters for TRA were estimated by a noncompartmental model using WinNonlin software (version 4.1; Pharsight, Mountain View,

TABLE 2

Pharmacokinetic parameters for total radioactivity after oral administration of $\left[{ }^{14} \mathrm{C}\right]$ ataluren to mice, rats, dogs, and humans

\begin{tabular}{|c|c|c|c|c|c|c|c|}
\hline Species & Sex & Dose & $\begin{array}{l}t_{1 / 2} \\
\text { (h) }\end{array}$ & $\begin{array}{l}\mathrm{T}_{\max } \\
\text { (h) }\end{array}$ & $\begin{array}{c}\mathrm{C}_{\max } \\
(\mu \mathrm{g} \mathrm{Eq} / \mathrm{ml})\end{array}$ & $\begin{array}{c}\mathrm{AUC}_{0-\mathrm{t}} \\
(\mu \mathrm{g} \\
\mathrm{Eq}^{* \mathrm{~h} / \mathrm{ml})}\end{array}$ & $\begin{array}{c}\mathrm{AUC}_{0-\infty} \\
(\mu \mathrm{g} \\
\mathrm{Eq}^{* \mathrm{~h} / \mathrm{ml})}\end{array}$ \\
\hline Mouse & Male & $300 \mathrm{mg} / \mathrm{kg}$ & 5.2 & 0.33 & 179 & 432 & 443 \\
\hline \multirow[t]{2}{*}{ Rat } & Male & $100 \mathrm{mg} / \mathrm{kg}$ & 4.9 & 1.0 & 271 & 2271 & 2274 \\
\hline & Female & & 5.1 & 0.5 & 275 & 2780 & 2784 \\
\hline Dog & Male & $250 \mathrm{mg} / \mathrm{kg}$ & 4.1 & 1.3 & 298 & 2249 & 2291 \\
\hline Human & Male & $1375 \mathrm{mg}$ & 6.4 & 1.0 & 77.3 & 394 & 395 \\
\hline
\end{tabular}

$\mathrm{AUC}_{0-\mathrm{t}}$, area under the plasma concentration-time curve from $0 \mathrm{~h}$ to last measurable concentration time point. AUC $\mathrm{A}-\infty$, area under the plasma concentration-time curve from $0 \mathrm{~h}$ to infinity. 


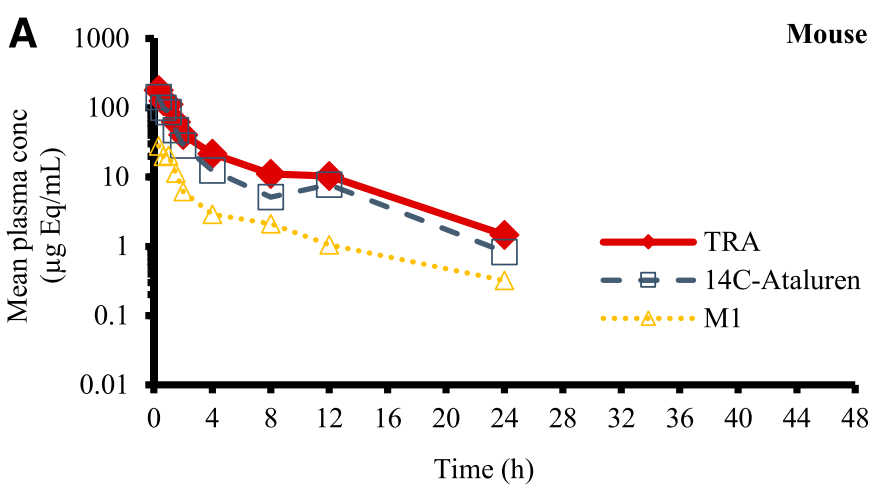

B
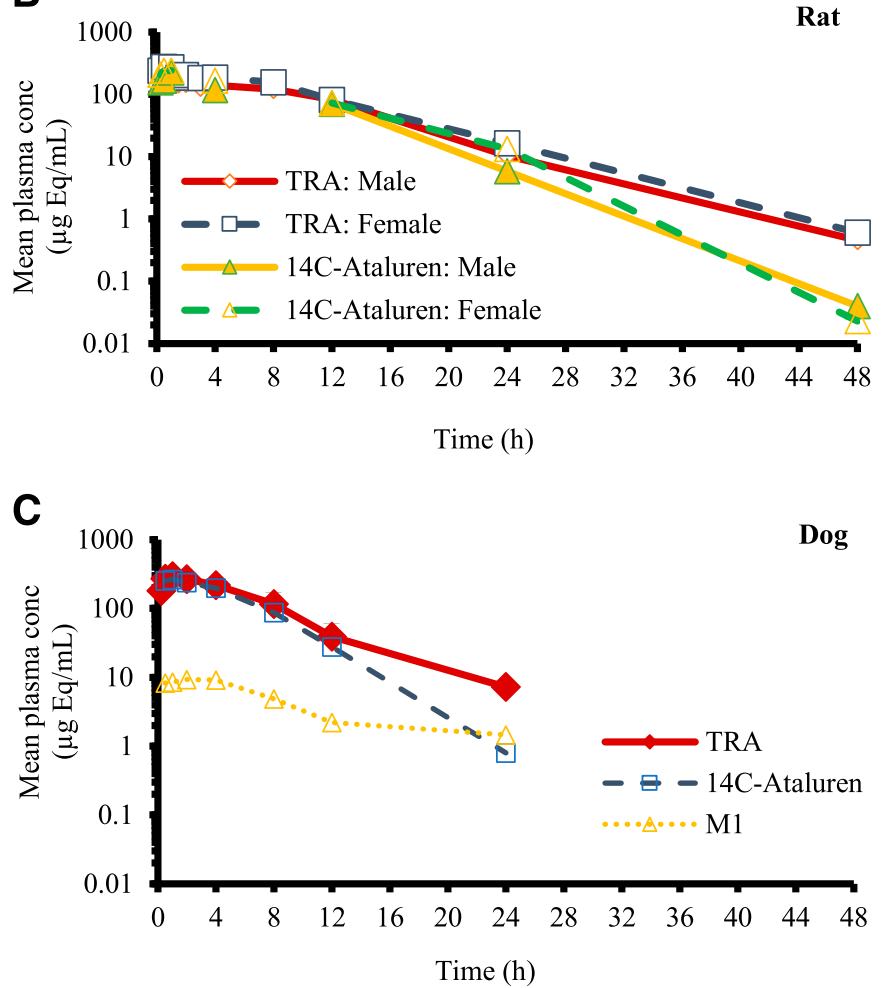

D

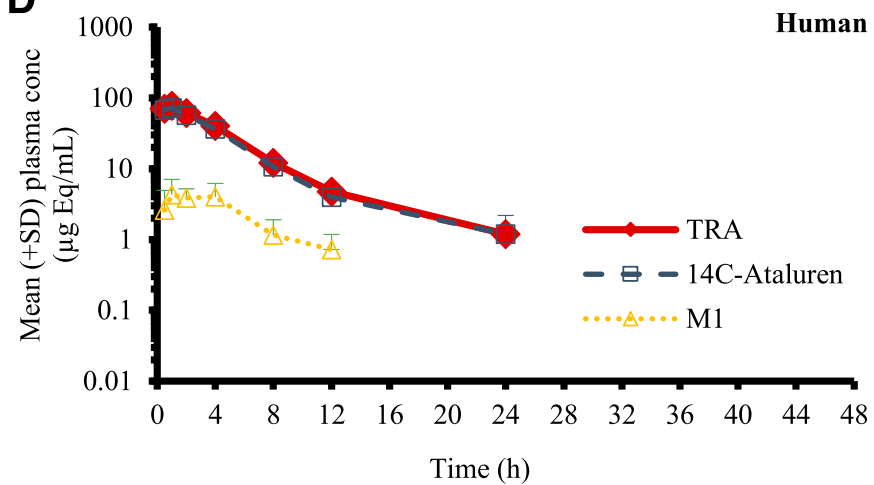

Fig. 1. Mean plasma concentration of TRA and metabolites vs. time profile after oral administration of $\left[{ }^{14} \mathrm{C}\right]$ ataluren to (A) male Tg.H2ras wild-type mice, (B) male and female Sprague-Dawley rats, (C) male beagle dogs, and (D) healthy human subjects.

CA). The PK parameters were obtained using the plasma TRA concentrations and nanogram or microgram Eq concentrations of $\left[{ }^{14} \mathrm{C}\right]$ ataluren and metabolites. The plasma area under the plasma concentration-time curve (AUC) was computed using the linear trapezoidal method. Time to maximum concentration $\left(\mathrm{T}_{\max }\right)$ and maximum concentration $\left(\mathrm{C}_{\max }\right)$ were observed values. The terminal slope $(\lambda)$ of the plasma concentration-time profile was determined by the method of least squares (log-linear regression of at least three data points). The terminal half-life $\left(t_{1 / 2}\right)$ was estimated as $\ln 2 / \lambda$.

\section{Results}

Excretion of Dosed Radioactivity. After oral administration of $\left[{ }^{14} \mathrm{C}\right]$ ataluren, most of the radioactivity was recovered in feces, which accounted for approximately $54 \%, 71 \%, 80 \%$, and $47 \%$ of the dose from mice, intact rats, dogs, and humans, respectively (Table 1). Urinary excretion accounted for $39 \%, 19 \%, 12 \%$, and $55 \%$ of the dose from mice, intact rats, dogs, and humans. For BDC rats, biliary excretion was significant, accounting for $82 \%$ of the dose, and no sex differences in either intact rats or BDC rats regarding the excretion of dosed radioactivity were observed. The excretion of dosed radioactivity was fast: approximately $90 \%$ of the dose was excreted within 48 hours for animals and within 72 hours for human subjects. Overall radioactivity recovery was $>93 \%$.

Pharmacokinetic Parameters. A summary of estimated PK parameters is given in Table 2, and the plasma concentration of TRA versus time curves is shown in Fig. 1. After oral administration, ataluren was rapidly absorbed, and $\mathrm{C}_{\max }$ was achieved within 1.5 hours (0.3-1.3 hours). After $\mathrm{C}_{\max }$ was reached, the TRA of plasma concentration-time profile exhibited a rapid decline and then

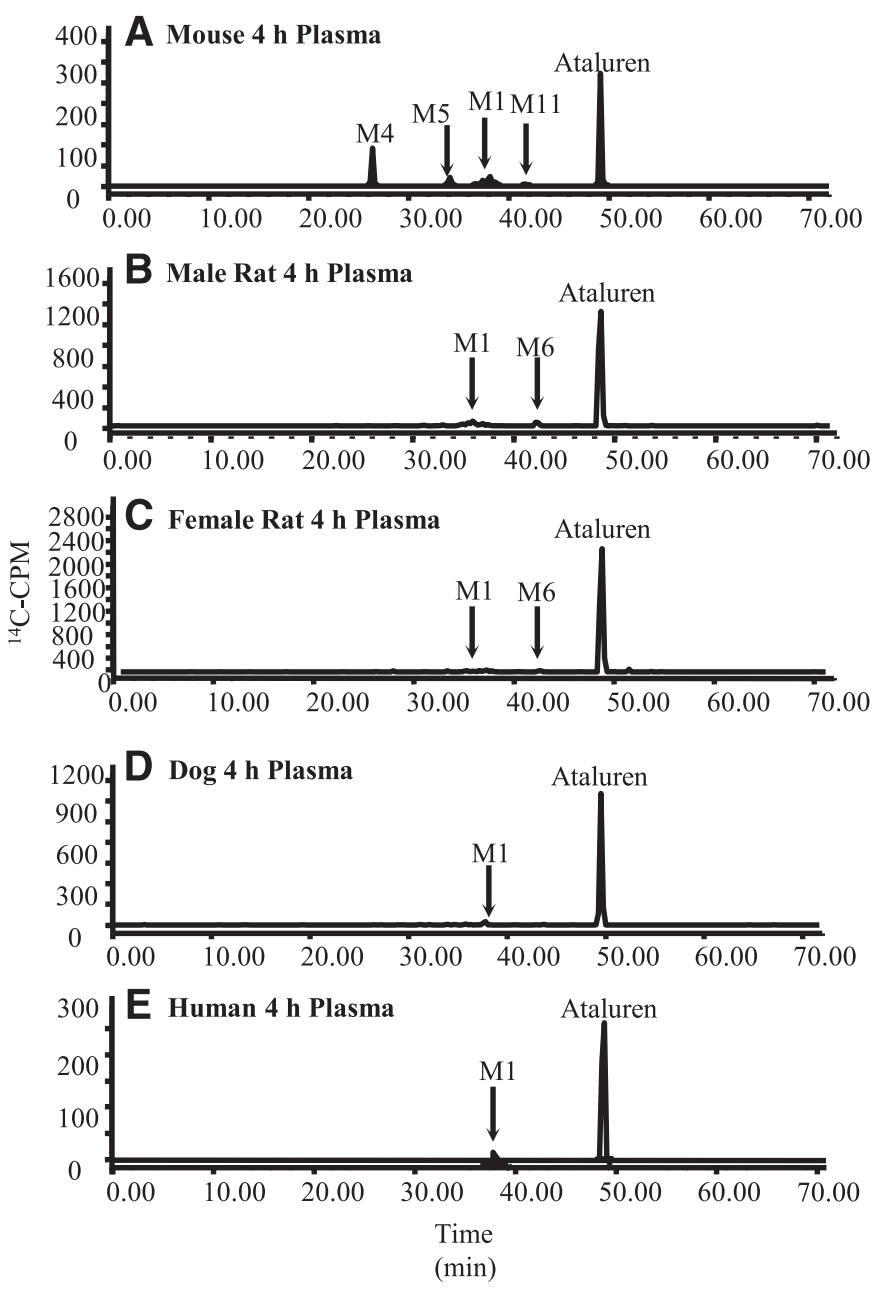

Fig. 2. Representative metabolic profile of plasma sample collected at 4 hours after oral administration of $\left[{ }^{14} \mathrm{C}\right]$ ataluren to $(\mathrm{A})$ mice, (B) male rats, (C) female rats, (D) dogs, and (E) humans. CPM, counts per minute. 
TABLE 3

Pharmacokinetic parameters for plasma metabolites after oral administration of $\left[{ }^{14} \mathrm{C}\right]$ ataluren to mice, rats, dogs, and humans

\begin{tabular}{|c|c|c|c|c|c|c|}
\hline \multirow[b]{2}{*}{ Species } & \multirow[b]{2}{*}{ Component } & \multirow{2}{*}{$\begin{array}{l}\mathrm{T}_{\max } \\
\text { (h) }\end{array}$} & \multirow{2}{*}{$\begin{array}{c}\mathrm{C}_{\max } \\
\mu \mathrm{g} \\
\mathrm{Eq} / \mathrm{ml}\end{array}$} & \multicolumn{3}{|c|}{$\mathrm{AUC}_{0-48 \mathrm{~h}}$} \\
\hline & & & & $\begin{array}{c}\mu \mathrm{g} \\
\mathrm{Eq} * \mathrm{~h} / \mathrm{ml}\end{array}$ & $\begin{array}{l}\% \text { of TRA } \\
\text { AUC }_{0-48 \mathrm{~h}}\end{array}$ & $\begin{array}{c}\% \text { of Ataluren } \\
\text { AUC }_{0-48 \mathrm{~h}}\end{array}$ \\
\hline \multirow[t]{4}{*}{ Mouse } & Ataluren & 0.33 & 143 & 302 & 69.9 & 100 \\
\hline & M1 (acyl glucuronide) & 0.33 & 28.2 & 65.6 & 15.2 & 21.8 \\
\hline & M4 & 4.00 & 4.06 & 34.5 & 8.00 & 11.4 \\
\hline & M11 & 0.33 & 1.58 & 4.57 & 1.06 & 1.52 \\
\hline \multirow[t]{3}{*}{ Male rat } & Ataluren & 1.00 & 226 & 1948 & 81.4 & 100 \\
\hline & M1 (acyl glucuronide) & 0.25 & 26.9 & 237 & 9.91 & 12.2 \\
\hline & M6 & 1.00 & 9.58 & 54.6 & 2.28 & 2.80 \\
\hline \multirow[t]{3}{*}{ Female rat } & Ataluren & 1.00 & 242 & 2456 & 88.3 & 100 \\
\hline & M1 (acyl glucuronide) & 0.25 & 15.5 & 140 & 5.02 & 5.69 \\
\hline & M6 & 0.50 & 9.65 & 31.9 & 1.15 & 1.30 \\
\hline \multirow[t]{3}{*}{ Dog } & Ataluren & 1.00 & 265 & 1852 & 82.4 & 100 \\
\hline & M1 (acyl glucuronide) & 2.00 & 9.00 & 97.9 & 4.35 & 5.28 \\
\hline & M5 & 8.00 & 3.00 & 43.1 & 1.92 & 2.33 \\
\hline \multirow[t]{2}{*}{ Human } & Ataluren & 1.00 & 72.4 & 373 & 93.4 & 100 \\
\hline & M1 (acyl glucuronide) & 1.00 & 4.30 & 28.1 & 7.00 & 7.60 \\
\hline
\end{tabular}

$\mathrm{AUC}_{0-48}$, area under the plasma concentration-time curve from 0 to $48 \mathrm{~h}$ postdose.

a more gradual terminal phase, with an estimated $t_{1 / 2}$ of $4.1-6.4$ hours, and was essentially nondetectable after 24 hours (48 hours for rat) postdose. The mean blood-to-plasma radioactivity concentration ratios were $0.51,0.44-0.49,0.65$, and 0.51 for mice, rats, dogs, and humans, indicating $\left[{ }^{14} \mathrm{C}\right]$ ataluren derived radioactivity was not significantly partitioned into the blood cellular component.
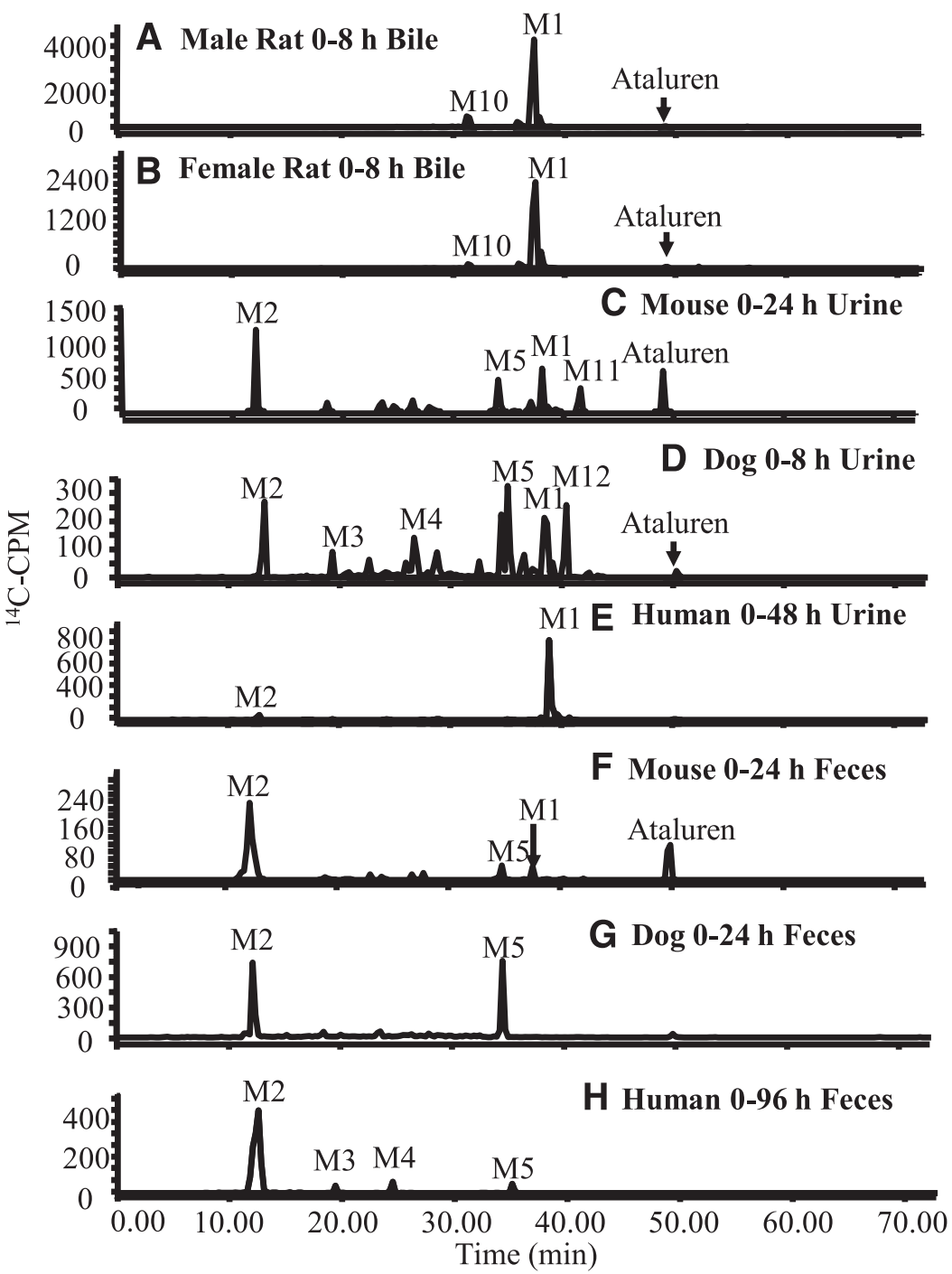

Fig. 3. Representative metabolic profile of bile, urine, and feces after oral administration of $\left[{ }^{14} \mathrm{C}\right]$ ataluren in (A) male rat bile; (B) female rat bile; $(\mathrm{C}-\mathrm{E})$ mouse, dog, and human urine; and $(\mathrm{F}-\mathrm{H})$ mouse, dog, and human fecal extract. CPM, counts per minute. 


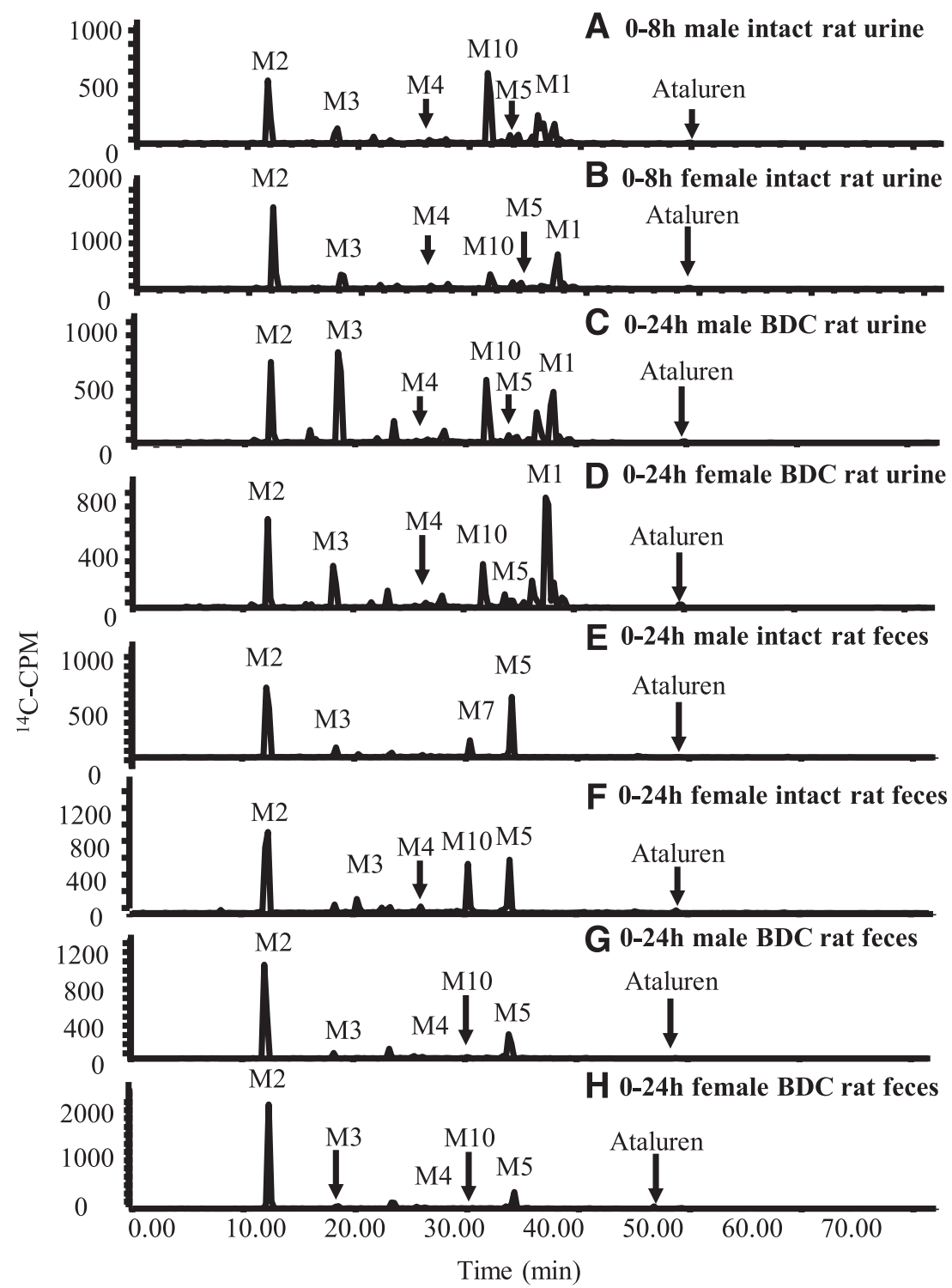

Fig. 4. Representative metabolic profile of urine and feces after oral administration of $\left[{ }^{14} \mathrm{C}\right]$ ataluren in $(\mathrm{A}-\mathrm{D})$ urine and $(\mathrm{E}-\mathrm{H})$ fecal extract from intact and BDC rats. $\mathrm{CPM}$, counts per minute.

Metabolic Profiles in Plasma. Representative metabolic profiles of ataluren in plasma from mice, rats, dogs, and humans at 4 hours postdose are shown in Fig. 2. The distribution of drug-related components and the PK parameters are summarized in Table 3. Similar plasma metabolic profiles were observed in all species. Ataluren was the dominant radioactive component in plasma, accounting for almost $>70 \%$ of plasma AUC of TRA. Ataluren acyl glucuronide (M1) was the most prominent metabolite and accounted for approximately $4 \%-15 \%$ of plasma AUC of TRA, or 5\%-22\% of plasma AUC of ataluren, and was the only detectable metabolite in human plasma. Formation of M1 was fast and peaked within 2 hours postdose. Oxadiazole reductive cleavage product (M4), glycine conjugate of ataluren, and fluorophenyl ring oxidation product (M6) were the minor circulating metabolites, accounting for $1 \%-8 \%$ of total plasma radioactivity in mouse or rat.

Metabolic Profiles in Bile, Urine, and Feces. Representative metabolic profiles of ataluren in bile, urine, and feces from mice, rats, dogs, and humans are shown in Figs. 3 and 4, and the distribution of drug-related components is summarized in Tables 4 and 5.

Ataluren was extensively metabolized after oral administration, and less than $2 \%$ of the dose was found as unchanged in excreta from rats, dogs, and humans, whereas approximately $5 \%$ and $7 \%$ of the dose was recovered as unchanged in mouse urine and feces, respectively. Ataluren acyl glucuronide (M1), accounting for approximately 50\%-60\% of the dose, was the dominant metabolite in human urine and in bile from male and female BDC rats. Ataluren acyl glucuronide and oxadiazole ring cleavage products (M2, M3, M4, or M5) were the prominent urinary metabolites in mice, rats, and dogs, whereas the latter were the major fecal metabolites in all species.

Identification of Metabolites. Similarities in HPLC retention times and mass spectrometric fragmentation patterns to available reference standards facilitated the identification of metabolites M1, M2, and M4. Structures of other metabolites were proposed based on their mass spectrometric fragmentation patterns relative to ataluren or the known metabolites. Proposed structures and metabolic pathways for the formation of the detected metabolites are shown in Fig. 5.

Unchanged ataluren in excreta was identified by direct comparison with a reference standard in terms of retention time and LC/MS spectral data. The characteristic positive electrospray ionization-mass spectrometry $[(+)$ ESI-MS] product ions of ataluren [at $\mathrm{m} / \mathrm{z}, 145$ (deprotonated 3-phenyl-1,2,4-oxadiazole ion), $\mathrm{m} / \mathrm{z} 123$ (2-fluorophenyl-oxo-methylium ion), and $\mathrm{m} / \mathrm{z}, 95$ (2-fluorobenzene-1-ylium ion)] were used for structural elucidation of the unknown metabolites. 
TABLE 4

Percentage of dose excreted as ataluren and metabolites in pooled bile, urine, and feces after single oral administration of $\left[{ }^{14} \mathrm{C}\right]$ ataluren to male and female rats

\begin{tabular}{|c|c|c|c|c|c|c|c|c|c|c|c|c|c|c|}
\hline \multirow{3}{*}{ Metabolite $^{\mathrm{a}}$} & \multicolumn{6}{|c|}{ Intact Rat ${ }^{\mathrm{b}}$} & \multicolumn{8}{|c|}{ BDC Rat ${ }^{b}$} \\
\hline & \multicolumn{3}{|c|}{ Male } & \multicolumn{3}{|c|}{ Female } & \multicolumn{4}{|c|}{ Male } & \multicolumn{4}{|c|}{ Female } \\
\hline & Urine & Feces & Total & Urine & Feces & Total & Bile & Urine & Feces & Total & Bile & Urine & Feces & Total \\
\hline M1 & 1.92 & 0.62 & 2.54 & 1.33 & 0.49 & 1.82 & 61.9 & 1.59 & 0.06 & 63.5 & 60.5 & 3.13 & 0.04 & 63.7 \\
\hline M2 & 6.07 & 26.8 & 32.9 & 5.26 & 26.3 & 31.5 & ND & 1.43 & 3.11 & 4.54 & ND & 1.29 & 3.34 & 4.63 \\
\hline M3 & 5.81 & 2.96 & 8.77 & 4.86 & 1.98 & 6.84 & ND & 2.56 & 0.21 & 2.77 & ND & 0.94 & 0.13 & 1.07 \\
\hline M4 & 0.31 & 0.92 & 1.23 & 0.36 & 1.12 & 1.48 & ND & 0.11 & ND & 0.11 & ND & 0.12 & 0.06 & 0.18 \\
\hline M5 & 0.15 & 14.5 & 14.7 & 0.89 & 6.38 & 7.27 & ND & 0.16 & 0.88 & 1.04 & ND & 0.21 & 0.56 & 0.77 \\
\hline M7 & ND & 4.16 & 4.16 & ND & 6.27 & 6.27 & ND & ND & 0.10 & 0.10 & ND & ND & 0.04 & 0.04 \\
\hline M9 & 1.29 & ND & 1.29 & 0.36 & 0.17 & 0.53 & 7.15 & 1.46 & 0.04 & 8.65 & 8.41 & 0.72 & 0.06 & 9.19 \\
\hline M10 & 0.91 & ND & 0.91 & 0.55 & ND & 0.55 & ND & 0.35 & ND & 0.35 & ND & 0.33 & ND & 0.33 \\
\hline M12 & 0.03 & ND & 0.03 & 0.01 & ND & 0.01 & ND & 0.02 & ND & 0.02 & ND & 0.24 & ND & 0.24 \\
\hline Ataluren & 0.09 & 0.24 & 0.33 & 0.05 & 0.29 & 0.34 & 1.07 & 0.05 & 0.03 & 1.15 & 0.64 & 0.11 & 0.03 & 0.78 \\
\hline
\end{tabular}

$\mathrm{ND}$, not detected by radioactivity.

${ }^{a}$ Structures of metabolites are shown in Fig. 5.

${ }^{b}$ The bile and urine were collected $0-48 \mathrm{~h}$ postdose, and fecal samples were collected $0-72 \mathrm{~h}$ postdose.

The metabolite $\mathrm{M} 1$ yielded a $[\mathrm{M}+\mathrm{H}]^{+}$at $m / z$, 461, which is $176 \mathrm{Da}$ higher than ataluren, suggesting M1 is the direct glucuronide derivative of ataluren. The synthetic ataluren- $O-1 \beta$-acyl glucuronide showed similar HPLC retention time, MS spectrum, and MS/MS fragmentation patterns to M1 in bile and urine samples.

The metabolite M2 is an oxadiazole ring cleavage product. The HPLC retention time and mass spectral data of M2 are all consistent with the synthetic reference standard.

M3 is another oxadiazole ring cleavage product. Liquid chromatography/positive electrospray ionization-mass spectrometry [LC/(+)ESIMS] analysis of M3 yielded a $[\mathrm{M}+\mathrm{H}]^{+}$at $m / z, 166,1$ Da higher than M2. M3 was identified as an oxidative deaminated product of M2 and was further confirmed by conversion of M2 into M3 under basic conditions.

The metabolite M4 is an oxadiazole ring reductive cleavage product. The HPLC retention time and mass spectral data of M4 are all consistent with the synthetic reference standard.

M5 is an oxidative deaminated product of M4 and was further confirmed by conversion of M4 into M5 under acidic conditions.

M6 is a fluorophenyl ring oxidation product of ataluren based on the observation of product ion at $\mathrm{m} / \mathrm{z} 139$ (16 Da higher than 2-fluorophenyloxo-methylium ion). However, the exact position of the oxidation could not be determined solely by MS/MS data.

M7 yielded a $[\mathrm{M}+\mathrm{H}]^{+}$at $\mathrm{m} / z, 304,19 \mathrm{Da}$ higher than ataluren, and the fragment ions at $\mathrm{m} / z, 111$ and 139 indicated oxidation on fluorophenyl ring. M7 is proposed to be an oxidation product of M5.
M10 had a $[\mathrm{M}+\mathrm{H}]^{+}$at $\mathrm{m} / z$ 464, 176 Da higher than M5. The fragment ions at $\mathrm{m} / \mathrm{z}, 288,270,149$, and 123 suggested that M10 is the acyl glucuronide of M5.

M11 showed a $[\mathrm{M}+\mathrm{H}]^{+}$at $m / z, 342,57$ Da higher than ataluren, suggesting a glycine conjugate of ataluren. Fragment ions at $\mathrm{m} / \mathrm{z} 267$, $239,145,123$, and 95 agreed well with proposed structure.

M12 yielded a molecular ion at $m / z, 428,143$ Da higher than ataluren. The presence of the fragment ions at $\mathrm{m} / \mathrm{z}, 95$ and 123 in the double-stage mass spectromety (MS2) and triple-stage mass spectromety (MS3) spectra of the parent ion at $\mathrm{m} / \mathrm{z} 428$ indicated that the fluorophenyl moiety was intact. Other fragment ions at $\mathrm{m} / \mathrm{z}, 145,267$, and 285 also indicated that the molecule contained intact parent drug moiety. Based on these results, M12 was proposed to be a carnitine conjugate of ataluren.

\section{Discussion}

In vitro metabolism studies showed that the major metabolic pathway for ataluren is via direct glucuronidation and that UGT1A9 is the major enzyme responsible for ataluren glucuronidation (Kong, et al., manuscript submitted).

The objective of the current study was to evaluate the metabolism and disposition of $\left[{ }^{14} \mathrm{C}\right]$ ataluren in mice, rats, dogs, and healthy human subjects. Consistent with in vitro metabolism results, the in vivo study found that phase I metabolism was negligible for ataluren. The main metabolism of ataluren involved glucuronidation, and no other circulatory

TABLE 5

Percentage of dose excreted as ataluren and metabolites in pooled urine and feces after single oral administration of $\left[{ }^{14} \mathrm{C}\right]$ ataluren to mice, dogs, and humans

\begin{tabular}{|c|c|c|c|c|c|c|c|c|c|}
\hline \multirow{2}{*}{ Metabolite $^{\mathrm{a}}$} & \multicolumn{3}{|c|}{ Mouse $^{b}$} & \multicolumn{3}{|c|}{$\operatorname{Dog}^{b}$} & \multicolumn{3}{|c|}{ Human $^{\text {b }}$} \\
\hline & Urine & Feces & Total & Urine & Feces & Total & Urine & Feces & Total \\
\hline M1 & 9.12 & 2.22 & 11.3 & 0.67 & ND & 0.67 & 48.6 & ND & 48.6 \\
\hline M2 & 8.16 & 24.5 & 32.7 & 3.22 & 19.0 & 22.2 & 1.98 & 36.6 & 38.6 \\
\hline M3 & ND & ND & ND & 1.41 & 0.88 & 2.29 & 0.24 & 1.41 & 1.65 \\
\hline M4 & 1.34 & 0.88 & 2.12 & 1.22 & 1.01 & 2.23 & 0.16 & 0.14 & 0.30 \\
\hline M5 & 3.99 & 2.51 & 6.50 & 2.46 & 16.9 & 19.4 & 0.17 & 1.94 & 2.11 \\
\hline M10 & 1.11 & 1.08 & 2.19 & ND & ND & ND & ND & ND & ND \\
\hline M11 & 3.68 & 0.19 & 3.87 & ND & ND & ND & ND & ND & ND \\
\hline M12 & ND & ND & ND & 0.70 & ND & 0.70 & ND & ND & ND \\
\hline Ataluren & 4.87 & 7.31 & 12.2 & 0.02 & 1.11 & 1.13 & 0.83 & 0.40 & 1.23 \\
\hline
\end{tabular}

$\mathrm{ND}$, not detected by radioactivity.

${ }^{a}$ Structures of metabolites are shown in Fig. 5.

${ }^{b}$ The urine and feces samples from mice, dogs, and humans were collected $0-48 \mathrm{~h}$ postdose, except for human fecal samples, which were collected $0-96 \mathrm{~h}$ postdose. 


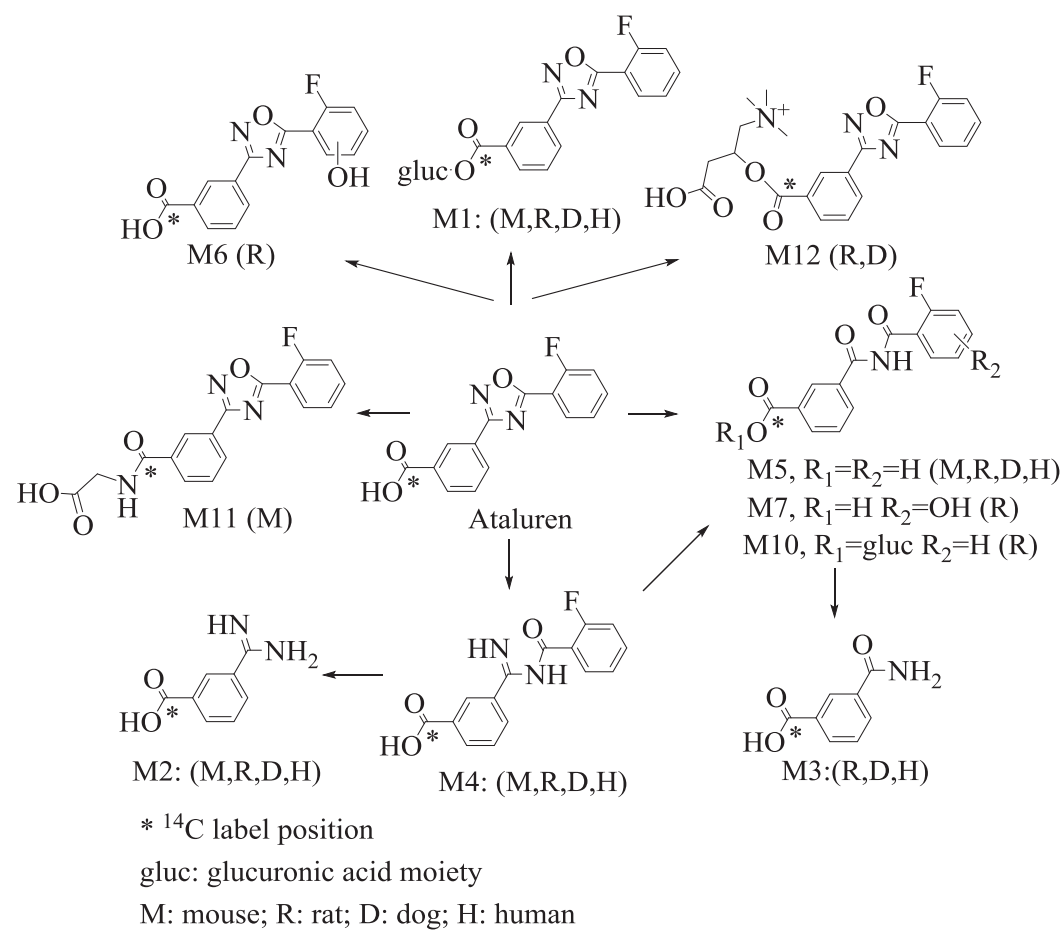

Fig. 5. Proposed metabolic pathways for ataluren after oral administration of ataluren in mice, rats, dogs, and humans. * ${ }^{14} \mathrm{C}$ label position; $\mathrm{D}$, dog; gluc, glucuronic acid moiety; H, human; M, mouse; R, rat. conjugation metabolite was observed in the investigated species. Ataluren was rapidly absorbed, and maximal plasma TRA was reached within 1.5 hours after oral administration for all species. The absorption rate was high, with more than $92 \%$ of the dose being absorbed in the BDC rats. The $t_{1 / 2}$ for plasma TRA was between 4.1 and 6.4 hours and was essentially nondetectable after 24 hours (48 hours for rat) postdose for all species. After oral administration of ataluren, urinary excretion was minor in rats and dogs, indicating that biliary and or fecal excretion were the major disposition pathways. In contrast, urinary excretion was greater, accounting for $39 \%$ and $55 \%$ of the dosed radioactivity in mice and humans, respectively.

Ataluren was the dominant radioactive component in plasma, accounting for $69.9 \%, 81.4 \%, 88.3 \%, 82.4 \%$, and $93.4 \%$ of plasma AUC of TRA in mouse, male and female rat, dog, and human, respectively. Ataluren acyl glucuronide (M1) was the most prominent circulating metabolite, accounting for $15.2 \%, 9.91 \%, 5.02 \%, 4.35 \%$, and $7.0 \%$ of plasma AUC of TRA or $21.8 \%, 12.2 \%, 5.7 \%, 5.3 \%$, and $7.6 \%$ of plasma AUC of ataluren in mice, male and female rats, dogs, and humans, respectively. M1 was the only detectable metabolite in human plasma.

Reductive cleavage of heterocycles is a common biotransformation pathway to drugs or drug candidates with an isoxazole, isothiazole, or oxadiazole moiety, and this process can be catalyzed by enzymes in liver or other tissues and by gut microflora (Yabuki et al., 1993; Viropharma Inc., 2002; Tschirret-Guth and Wood, 2003; Bateman et al., 2006; Zhang et al., 2008). For ataluren, oxadiazole ring cleavage could be an enzyme-mediated reaction since they were detected in both plasma and urine; however, high levels of M2 and M5 in feces were most probably formed by the microbial flora in the intestine from unabsorbed ataluren and from metabolites such as ataluren acyl glucuronide after biliary excretion.

Ataluren acyl glucuronide (M1) was the prominent metabolite in plasma in all species. Like other acyl glucuronides of carboxylic acid-containing drugs, ataluren acyl glucuronide is not stable under certain conditions, such as high $\mathrm{pH}$ and high temperature, and migration isomers were observed in plasma and urine samples in current studies.
In these studies, plasma extract and urine samples were not preserved in acidic conditions prior to radio profiling and/or LC/MS analysis. Therefore, acyl glucuronide migration observed in these studies most probably resulted from ex vivo migration under the conditions of the sample preparation. In the follow-up studies, to fully characterize ataluren- $O-1 \beta$-acyl glucuronide stability in mouse, rat, dog, and human plasma after a single oral dose or multiple oral doses, great caution was exercised to prevent ex vivo migration of ataluren- $O-1 \beta$-acyl glucuronide during sample collection, storage, and processing (e.g., blood samples were maintained on ice and were centrifuged as soon as possible for plasma collection; plasma samples were stored at or below $-70^{\circ} \mathrm{C}$ before analysis and, after thaw on wet ice, were quickly extracted with acetonitrile containing $1 \%$ formic acid for LC/MS analysis; and all samples were stabilized and analyzed under acid conditions). Under these conditions, ataluren acyl glucuronide migration isomers were not detected, and ataluren $O-1 \beta$-acyl glucuronide was the only form of ataluren acyl glucuronide in mouse, rat, dog, and human plasma (results to be published in a separate paper).

In summary, this investigation demonstrated that ataluren was well absorbed and cleared primarily by metabolism in mice, rats, dogs, and humans. Biliary secretion was the major route for elimination of drug-related radioactivity in BDC rats. The primary in vivo metabolic pathways for ataluren in mice, rats, dogs, and humans were direct conjugation with glucuronic acid (M1), glycine (M11), carnitine (M12), oxidation (M6), and oxadiazole ring cleavage products (M2, M3, M4, and M5), and ataluren acyl glucuronide (M1) was the only detectable metabolite in human plasma. There were no sex differences in the metabolism and disposition of ataluren in the rats, and the major metabolic and clearance pathways in humans are similar to animal species. Understanding the metabolism of ataluren is key for evaluating the efficacy and safety of the long-term administration of the drug, which is necessary for the treatment of nmDMD.

\section{Authorship Contributions}

Participated in research design: Kong, Ma, Northcutt, Almstead. Conducted experiments: Kong, Ma. 
Contributed new reagents or analytic tools: Hwang.

Performed data analysis: Kong, Ma, Northcutt, Babiak, Almstead.

Wrote or contributed to the writing of the manuscript: Kong, Ma, Goodwin, Northcutt, Babiak, Almstead, McIntosh.

\section{References}

Aartsma-Rus A, Van Deutekom JC, Fokkema IF, Van Ommen GJ, and Den Dunnen JT (2006) Entries in the Leiden Duchenne muscular dystrophy mutation database: an overview of mutation types and paradoxical cases that confirm the reading-frame rule. Muscle Nerve 34:135-144.

Bateman KP, Trimble L, Chauret N, Silva J, Day S, Macdonald D, Dube D, Gallant M, Mastracchio A, Perrier H, et al. (2006) Interspecies in vitro metabolism of the phosphodiesterase-4 (PDE4) inhibitor L-454,560. J Mass Spectrom 41:771-780.

Bladen CL, Salgado D, Monges S, Foncuberta ME, Kekou K, Kosma K, Dawkins H, Lamont L, Roy AJ, Chamova T, et al. (2015) The TREAT-NMD DMD Global Database: analysis of more than 7,000 Duchenne muscular dystrophy mutations. Hum Mutat 36:395-402.

Bushby K, Finkel R, Birnkrant DJ, Case LE, Clemens PR, Cripe L, Kaul A, Kinnett K, McDonald C, Pandya S, et al.; DMD Care Considerations Working Group (2010a) Diagnosis and management of Duchenne muscular dystrophy, part 2: implementation of multidisciplinary care. Lancet Neurol 9:177-189.

Bushby K, Finkel R, Birnkrant DJ, Case LE, Clemens PR, Cripe L, Kaul A, Kinnett K, McDonald C, Pandya S, et al.; DMD Care Considerations Working Group (2010b) Diagnosis and management of Duchenne muscular dystrophy, part 1: diagnosis, and pharmacological and psychosocial management. Lancet Neurol 9:77-93.

Bushby K, Finkel R, Wong B, Barohn R, Campbell C, Comi GP, Connolly AM, Day JW, Flanigan KM, Goemans N, et al.; PTC124-GD-007-DMD STUDY GROUP (2014) Ataluren treatment of patients with nonsense mutation dystrophinopathy. Muscle Nerve 50:477-487.

Culbertson MR (1999) RNA surveillance. Unforeseen consequences for gene expression, inherited genetic disorders and cancer. Trends Genet 15:74-80.

Finkel RS, Flanigan KM, Wong B, Bönnemann C, Sampson J, Sweeney HL, Reha A, Northcut VJ, Elfring G, Barth J, et al. (2013) Phase 2a study of ataluren-mediated dystrophin production in patients with nonsense mutation Duchenne muscular dystrophy. PLoS One 8:e81302.

Henricson EK, Abresch RT, Cnaan A, Hu F, Duong T, Arrieta A, Han J, Escolar DM, Florence JM, Clemens PR, et al.; CINRG Investigators (2013) The cooperative international neuromuscular research group Duchenne natural history study: glucocorticoid treatment preserves clinically meaningful functional milestones and reduces rate of disease progression as measured by manual muscle testing and other commonly used clinical trial outcome measures. Muscle Nerve 48:55-67.

Mah JK (2016) Current and emerging treatment strategies for Duchenne muscular dystrophy. Neuropsychiatr Dis Treat 12:1795-1807.

McDonald CM, Campbell C, Torricelli RE, Finkel RS, Flanigan KM, Goemans N, Heydemann P, Kaminska A, Kirschner J, Muntoni F, et al:- Clinical Evaluator Training Group; ; ACT DMD Study Group (2017) Ataluren in patients with nonsense mutation Duchenne muscular dystrophy (ACT DMD): a multicentre, randomised, double-blind, placebo-controlled, phase 3 trial. Lancet 390:1489-1498.

Mendell JT and Dietz HC (2001) When the message goes awry: disease-producing mutations that influence mRNA content and performance. Cell 107:411-414.

Muntoni F, Torelli S, and Ferlini A (2003) Dystrophin and mutations: one gene, several proteins, multiple phenotypes. Lancet Neurol 2:731-740.

Petrof BJ, Shrager JB, Stedman HH, Kelly AM, and Sweeney HL (1993) Dystrophin protects the sarcolemma from stresses developed during muscle contraction. Proc Natl Acad Sci USA 90: $3710-3714$.

Tschirret-Guth RA and Wood HB (2003) Substituent effect on the reductive N-dearylation of 3-(indol-1-yl)-1,2-benzisoxazoles by rat liver microsomes. Drug Metab Dispos 31:999-1004.

Viropharma Inc. (2002) Antiviral Drug Advisory Committee Briefing Document, Picovir (pleconaril), NDA: 21-245.

Welch EM, Barton ER, Zhuo J, Tomizawa Y, Friesen WJ, Trifillis P, Paushkin S, Patel M, Trotta CR, Hwang S, et al. (2007) PTC124 targets genetic disorders caused by nonsense mutations. Nature 447:87-91.

Yabuki M, Shono F, Nakatsuka I, and Yoshitake A (1993) Novel cleavage of the 1,2,4-oxadiazole ring in rat metabolism of SM-6586, a dihydropyridine calcium antagonist. Drug Metab Dispos 21:1167-1169.

Zhang D, Raghavan N, Chen SY, Zhang H, Quan M, Lecureux L, Patrone LM, Lam PY, Bonacorsi SJ, Knabb RM, et al. (2008) Reductive isoxazole ring opening of the anticoagulant razaxaban is the major metabolic clearance pathway in rats and dogs. Drug Metab Dispos 36:303-315.

Address correspondence to: Dr. Ronald Kong, PTC Therapeutics Inc., 100 Corporate Court, South Plainfield, NJ 07080. E-mail: rkong@ptcbio.com 